Recebido: $11 / 01 / 2015$

Aprovado: 21/03/2015

\title{
Adam Smith e a sociedade comercial
}

Pedro Henrique Soares Santos*

Resumo: $O$ presente artigo aponta as correlações entre os trabalhos de filosofia moral e de economia política de Adam Smith, intentando expor a coerência do pensamento deste filósofo. $\mathrm{O}$ quadro que emerge é de uma defesa das virtudes advindas de uma sociedade comercial e as soluções e remédios para seus possíveis desvios e vícios.

Palavras-chave: Economia política; Filosofia moral; Sociedade comercial.

Abstract: The present article points out the correlation between the works of political economy and moral philosophy of Adam Smith, in order to stress the coherence of his philosophical thought. The emerging picture is one of defense of the virtues aroused from a commercial society and the solutions and remedies for its possible deviations and vices.

Key-words: Political economy; Moral philosophy; Commercial society.

\footnotetext{
* Mestrando em História pela Universidade de Brasília. Estuda atualmente as relações entre os direitos de cidadania e as práticas de recrutamento e de castigo no Exército do Brasil no Primeiro Reinado. Este texto foi realizado sob a orientação da Professora Tereza Cristina Kirschner em disciplina ofertada em 2012. E-mail para contato: soaresantos.his@gmail.com
} 
Two principles in human nature reign; Self-love to urge, and Reason to restrain; nor this a good, nor that a bad we call, each works its end, to move or govern all.

Alexander Pope, Essay on man, Epistle II.

Le cour a ses raisons que la raison ne connaît point.

Blaise Pascal, Penseés, fragmento 397.

\section{Introdução}

Adam Smith foi um importante filósofo escocês do século XVIII e é o autor de uma das mais importantes obras sobre economia política: A riqueza das nações. O caráter seminal desta obra foi reconhecido logo quando publicada e rendeu à Smith grande fama. Por essa razão, seus demais trabalhos de filosofia moral foram relegados a segundo plano e sua imagem de "pai do capitalismo" ou de "pai da economia moderna" foi criada. Muitos estudiosos de seus textos chegaram a afirmar que haveria, na verdade, uma grande incongruência entre sua primeira obra, Teoria dos sentimentos morais, e suas considerações posteriores sobre economia política (HIMMELFARB, 2011: 77). Como resume Robert Fulton:

In dealing with Smith's thought one is confronted with the apparent contrast between the point of view of his two chief writings - a difficulty which has found its way into German social thought as "das Adam Smith - Problem". Attempts at solution have by differentiating the Smith of 1759 from the Smith of 1776, the change - being attributed chiefly to his contact, in the interim, with the Physiocrats in France. The writer is convinced, however, that this conflict is only a seeming one (though hardly less harmful in its historical effect than if genuine) (FULTON, 1963: 39).

Essa interpretação, no entanto, não considera as várias revisões que Smith realizou em sua Teoria pouco antes de sua morte, na qual acrescentou nova parte. Essa tendência de análise vem se revertendo nas últimas décadas, com a publicação de vários trabalhos que visam resgatá-lo como filósofo moral.

É nesta perspectiva que este artigo se insere. Especificamente, pretende-se examinar a visão de Smith sobre a sociedade comercial a partir de sua primeira obra, Teoria dos sentimentos morais. $\mathrm{O}$ artigo divide-se em três partes: uma síntese de sua biografia, sua defesa da sociedade comercial e por fim, suas críticas e soluções.

\section{Smith: uma breve biografia}

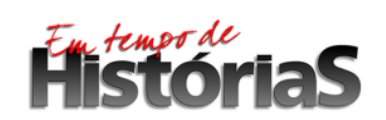


Filho único de Adam Smith e Margaret Douglas, Adam Smith nasceu em 5 de junho de 1723, na cidade portuária escocesa de Kirkaldy, somente dezesseis anos após o Ato de União que ligou politicamente Inglaterra e Escócia. ${ }^{1}$

Adam Smith iniciou seus estudos universitários muito jovem, aos catorze anos, na universidade de Glasgow. Lá entrou em contato com a filosofia moral de Francis Hutcheson, com o pensamento estóico e com os teóricos do direito natural moderno. Pouco tempo depois, foi para Oxford e dedicou-se aos clássicos gregos e latinos, além de estudar matemática e ciência moderna.

Aos vinte e cinco anos de idade começou a ganhar notoriedade no mundo intelectual ao ministrar uma série de palestras na universidade de Edimburgo. Pouco tempo depois, em 1751, foi indicado para ser professor de retórica e lógica e, posteriormente, de filosofia moral na Universidade de Glasgow. Suas conferências sobre ética formaram o núcleo de seu primeiro livro, Teoria dos sentimentos morais, publicado em 1759. O livro foi bem recebido tanto na Inglaterra quanto no continente e até a morte do autor, em 1790, obteve seis edições e até o fim do século, três traduções para francês e duas para o alemão. (MÜLLER, 1995: 24).

Sua obra chamou a atenção de Charles Townshed, um membro do Parlamento britânico. Em 1763, ele convidou Smith para ser o tutor de Henry Scott, duque de Buccleuch, e acompanhá-lo em suas viagens:

e os termos liberais em que a proposta lhe foi apresentada, somados ao forte desejo de visitar o continente europeu, levaram-no a renunciar ao seu cargo em Glasgow. [...] Mas fossem quais fossem as luzes que suas viagens lhe propiciaram como estudioso da natureza humana, provavelmente foram úteis em grau ainda maior, porque o capacitaram a aperfeiçoar aquele sistema de economia política, cujos princípios já expusera em suas conferências e Glasgow, e que agora, depois de muito estudo, preparava para lançá-lo ao público (STEWART; SMITH, 2002: XLIX-L).

O livro sobre economia política a que se refere Stewart é o famoso A riqueza das nações, ${ }^{2}$ lançado em 1776. Muitos autores hoje concordam, contudo, que as ideias apresentadas nesse livro são anteriores, provavelmente de 1755, o que confirma a afirmação

\footnotetext{
${ }^{1}$ A união política foi de grande importância para o desenvolvimento econômico das Lowlands escocesas, que entraram no circuito de comércio inglês. A prosperidade dessas regiões contrastava com as sociedades tribais existentes nas Highlands, onde o governo central era quase ausente e o poder era disputado com os chefes dos clãs. A existência desses diferentes estágios de organização social levariam muitos autores escoceses a pensarem em uma história natural em estágios de desenvolvimento, chamada história conjuntural, tal como fez David Hume (MÜLLER, 1995: 16).

${ }^{2} \mathrm{O}$ título original é mais extenso, mas por motivos editoriais acabou sendo comprimido: An inquiry into the nature and causes of the wealth of nations. Em tradução livre: Uma investigação sobre a natureza e as causas da riqueza das nações.
} 
de seu primeiro biógrafo. A repercussão da obra foi grande. Gertrude Himmelfarb afirma que as primeiras quinhentas cópias foram vendidas em seis meses - em um período em que o mercado editorial estava dando seus primeiros passos e o número de analfabetos era elevado , seguidas de cinco edições até 1790, além de traduções para o francês, alemão, italiano, dinamarquês e espanhol. Este trabalho atraiu grandes políticos e pensadores, que depois se declaram seus discípulos: Edmund Burke, Thomas Paine, Edward Gibbon, Richard Price, William Pitt e Lorde North (STEWART; SMITH, 2002: LI).

Em uma viagem à França, Smith entrou em contato com famosos pensadores franceses: Turgot, Quesnay, Necker, d'Alembert, Helvetius, Voltaire, dentre outros. Nesse país, aproveitou também para coletar informações sobre os impostos e a administração com vistas à escrita de seu livro.

Retornou para a Inglaterra em 1766, residindo inicialmente em Kirkaldy e depois em Londres. Vivia da pensão fornecida pelo duque de Buccleuch. Dois anos após a publicação de A riqueza das nações, em 1778, foi nomeado, a pedido do duque, Diretor de Alfândega em Edimburgo, cargo que ocupou até os últimos anos de vida (STEWART; SMITH, 2002: LXXIV).

Neste posto, Smith manteve contato direto com grandes comerciantes e membros da burguesia e percebeu os males que o desenvolvimento do comércio acarretava, tanto no aspecto moral quanto social. Talvez essa experiência tenha tido alguma influência em sua última revisão da Teoria dos sentimentos morais, levando-o a enfatizar a questão das virtudes. Como afirma Müller:

Though his days were filled with the concerns of trade and revenue, his mind seems to have turned back to the questions of ethic and the social formation of character central to the Theory of Moral Sentiments, which he substantially revised and expanded (MÜLLER, 1995: 26).

Apesar de todos os problemas, Smith sempre defendeu esse tipo de sociedade. Antes, contudo, de passarmos para a análise dos problemas que envolviam essa sociedade comercial e as soluções sugeridas por Smith, vejamos as bases com as quais o filósofo a defendia.

\section{Em defesa da sociedade comercial}

Smith acreditava que a sociedade comercial trazia três benefícios importantes: a expansão da civilização, a promoção da liberdade do homem, o alívio da pobreza com o

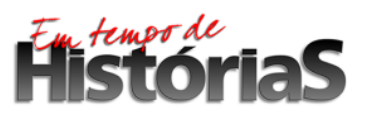


aumento da produção e circulação de produtos e, em algum grau, da distribuição de bens materiais. Em outras palavras, ele a defendia pelos seus benefícios públicos, particularmente seus efeitos para os mais pobres e fracos (MÜLLER, 1995: 18).

O filósofo escocês percebeu no crescimento do comércio de seu tempo um potencial projeto civilizatório. Ele analisou as condições necessárias para o desenvolvimento do comércio e percebeu que ele estimulava determinadas formas de comportamento virtuoso. Para um comerciante conseguir crédito no século XVIII, quando havia pouco controle burocrático-administrativo que ligava credor e devedor, ele deveria manter sua palavra, ter autocontrole e um comportamento prudente. Já a situação de trocas de produtos, levava as partes negociantes a olharem a situação de cada um, a ponderar sobre a perspectiva alheia e calibrar as próprias demandas. Tal atitude, na visão de Smith, é baseada em nossos sentimentos de simpatia e os fortalece na medida em que a praticamos (GRISWOLD JR., 1999: 295-298).

O mercado, assim, exortava os homens a um controle maior de suas emoções, encorajando-os a condutas respeitáveis. A integração resultante do comércio impulsionaria os homens a se tratarem com decência, mesmo entre aqueles em que havia grande distância social. Na perspectiva do filósofo escocês, dados os incentivos corretos para o mercado, as paixões humanas poderiam ser canalizadas para uma forma de comportamento mais moral e beneficente (MÜLLER, 1995: 94). Para Smith, o projeto civilizatório agregava, portanto, a criação e expansão da riqueza e o desenvolvimento moral da sociedade.

A preocupação com o desenvolvimento moral da sociedade existira antes de Smith, notadamente entre os pensadores clássicos e humanistas. Contudo, diferiam quanto ao foco principal das virtudes, quais deveriam ser incentivadas e como promovê-las. Os últimos defendiam a promoção das grandes virtudes dos governantes e soberanos e a partir de seu comportamento virtuoso buscar-se-ia aperfeiçoar as instituições. Smith, por sua vez, preocupava-se em melhorar o caráter da maioria da sociedade por meio do incentivo de virtudes de menor grandeza, priorizando o papel das instituições nesse aprimoramento. Ele considerava os sentimentos morais como universais - presentes em todos os seres humanos. $\mathrm{O}$ grau de seu desenvolvimento, no entanto, seria variável, a depender das demandas e incentivos sociais existentes, estes sujeitos às mudanças históricas. ${ }^{3}$ As instituições que Smith

\footnotetext{
${ }^{3}$ Como ele escreveu: "In general, the style of manners which takes place in any nation, may commonly upon the whole to be said to be that which is most suitable to its situation. (...) Hardiness is the character most suitable to the circumstances of a savage; sensibility to those of one who lives in a very civilized society". (Apud Müller: 1995: 95).
} 
reputava capazes de auxiliar a esmerar o comportamento humano seriam a justiça imparcial, a educação para amplos setores da população e o próprio mercado.

As instituições poderiam contribuir no controle das paixões humanas e propiciar um grau maior de liberdade civil. Uma vez que os homens fossem estimulados a comportamentos mais decentes, eles poderiam escapar da subordinação política pessoal de nobres e eclesiásticos e passariam a sujeitar seus desejos egoístas às regras sociais estabelecidas (MÜLLER, 1995: 99). Essa concepção foi exposta de maneira clara por Edmund Burke, um leitor de Adam Smith, que afirmou em uma de suas cartas:

Men are qualified for civil liberty in exact proportion to their disposition to put moral chains upon their appetites [...] Society cannot exist unless a controlling power upon will and appetite be placed somewhere, and the less of it there is within, the more there must be without (Apud MÜLLER, 1995: 99).

Por fim, ao defender a quebra dos monopólios existentes no Reino Unido de seu tempo e a instalação de um livre mercado, Smith pensava nos ganhos que grande parte da população teria. Com a competição, principalmente de produtos importados, os preços tenderiam a baixar e a população mais pobre poderia consumir mais ou, ao menos, mitigar sua miséria. Ao conjunto articulado dessas noções de Smith, J. Poccok deu o nome de "humanismo comercial” (POCOCK, 2003: 98).

Não obstante os grandes benefícios da sociedade comercial, sobretudo no que se refere à expansão do mercado e da riqueza, ela também poderia promover vícios e corromper os homens. Smith, longe de justificar esses vícios como fez Mandeville, analisa os problemas da sociedade comercial e propõe soluções a partir do refinamento das virtudes.

\section{O sistema de virtudes e o combate à corrupção na sociedade comercial}

A crítica de Adam Smith à sociedade comercial, e ao amor ao ganho e ao prazer por ela inspirados, baseia-se nas considerações sobre a corrupção da moral individual e dos laços cívicos.

Para falar da corrupção dos sentimentos morais, Smith inicia suas considerações a partir da análise da simpatia ${ }^{4}$. Ele argumenta que sempre estamos mais dispostos a simpatizar

\footnotetext{
${ }^{4}$ Smith define a simpatia a partir da etimologia da palavra: "A palavra simpatia, em seu significado mais apropriado e original, denota nossa solidariedade (fellow-feeling) para com os sofrimentos, e não para com as alegrias de outros" (SMITH: 2002: 51).
} 
com a alegria do que com a dor ${ }^{5}$, e, por isso, "exibimos nossa riqueza e escondemos nossa pobreza" (SMITH, 2002: 59). Seria pela vontade de ser "tratado com simpatia" que buscaríamos melhorar nossa situação:

Pois de onde, então, origina-se essa emulação que perpassa todas as diferentes ordens de homens, e a que benefícios aspiramos com esse grande propósito da vida humana a que chamamos melhorar nossa condição? Ser notado, servido, tratado com simpatia, complacência e aprovação, são todos os benefícios a que podemos aspirar. [...] O homem rico jacta-se de sua riqueza, porque sente que naturalmente isso dirige sobre si a atenção do mundo. [...] O homem pobre, ao contrário, envergonha-se de sua pobreza. Sente que ou essa situação o coloca fora da vista das pessoas, ou que se o percebem, têm quase nenhuma solidariedade para com a miséria e aflição de que é vítima (SMITH, 2002: 60).

É essa disposição de simpatizar com os mais ricos e poderosos, e, portanto, os mais notados da sociedade, que fundamenta a distinção social:

Sobre essa disposição da humanidade a partilhar de todas as paixões dos ricos e poderosos fundamenta-se a distinção social e a ordem da sociedade. Nossa obsequiosidade para com nossos superiores se origina mais frequentemente de nossa admiração pelas vantagens de sua situação do que de qualquer expectativa pessoal de benefício advindo de sua boa vontade (SMITH, 2002: 62).

Não obstante, o amor ao reconhecimento, a admiração pela riqueza e pelos status dos poderosos, apesar de ser um combustível que anima a ambição de melhorar nossa condição social é a razão "da corrupção de nossos sentimentos morais":

Essa disposição de admirar, quase de adorar os ricos e poderosos, e desprezar ou pelo menos negligenciar pessoas de condição pobre ou mesquinha, embora necessário tanto para estabelecer quanto para manter a distinção de hierarquias e a ordem da sociedade, é ao mesmo tempo a grande e mais universal causa de corrupção de nossos sentimentos morais. [...] Merecer, obter, saborear o respeito e admiração dos homens são os grandes objetos da ambição e emulação. Dois diferentes caminhos são apresentados, levando igualmente à obtenção desse tão desejado objeto; um, pelo estudo da sabedoria e pela prática da virtude; outro, pela aquisição de fortuna e grandeza (SMITH, 2002: 72-73).

Essa vaidade e ambição, estimuladas pela sociedade comercial, levariam o homem a uma situação de inquietude ${ }^{6}$ e ansiedade. De acordo com Hanley, a análise de Smith segue

\footnotetext{
5 “É agradável simpatizar com a alegria; e sempre que a inveja não se oponha a isso, nosso coração entrega-se com satisfação aos mais elevados transportes dessa emoção encantadora. Mas é doloroso acompanha a dor, e sempre dela partilhamos com relutância”. (Smith: 2002: 54).

${ }^{6}$ No original, restlessness.
} 
uma tradição que vai de Pascal, passando por Rousseau que identifica no sucesso comercial uma vida de ansiedade e não de tranquilidade (HANLEY, 2009: 38). Tal como Smith escreve: "essa aquisição o [o homem rico] faz perder o direito a todo ócio, toda a tranquilidade, toda a despreocupada segurança." (SMITH, 2002: 61).

Mas, esse é apenas um lado da questão - a mudança das relações do eu para consigo mesmo leva a uma vida inquieta, e, consequentemente, infeliz. O comércio para Smith também transforma as relações interpessoais, que passam a se basear em duplicidade e engano (SMITH, 2002: 41). Ao se amar o reconhecimento dos outros, essa sociedade encoraja mais a aparência - no sentido do comportamento que os outros observam - do que a essência das pessoas, ou, em termos rousseaunianos, o paraître suplanta o être (HANLEY, 2009: 41).

Esse seria o caso do homem vaidoso, aquele que deseja ser visto pelo que não é, que ama ser louvado sem ter mérito e faz de tudo para conquistar a estima e aprovação alheia:

O homem vaidoso não é sincero e, no fundo do seu coração, raramente está convencido da superioridade que deseja que lhe atribuas. [...] Portanto, se demonstras vê-lo em cores diferentes, talvez as suas verdadeiras cores, fica muito mais mortificado do que ofendido. [...] Longe de desprezar a tua estima, corteja-a com a mais ansiosa perseverança. Longe de desejar mortificar tua auto-estima, fica feliz em cultivá-la, na esperança de que em troca cultives a dele. [...]. Assim, suas roupas, sua equipagem, seu modo de vida, anunciam uma posição e uma fortuna maiores do que as que realmente possui (SMITH, 2002: 319).

Esse amor pelo reconhecimento baseado em falsas atitudes levaria a uma divisão entre mérito e o avanço na escala social. Para Smith, isso seria o retrato de uma sociedade corrompida (HANLEY, 2009: 41):

a adulação e falsidade muito frequentemente prevalecem sobre mérito e habilidades. Em tais círculos sociais [os altos], as habilidades em agradar são mais consideradas do que as habilidades em servir [...] Todas as grandes e veneráveis virtudes, todas as virtudes que podem tanto servir para o conselho, o senado ou o campo de batalha, são concebidas com extremo desprezo e riso pelos aduladores insolentes e insignificantes que habitualmente figuram nessas sociedades corruptas (SMITH, 2002: 74-75).

Hanley afirma que a ansiedade, inquietude e duplicidade desse homem vaidoso, além dos efeitos perniciosos de tais vícios per se, ainda obliterariam sua capacidade de reconhecer a verdadeira excelência, condenando-o a uma mediocridade moral. Esse entendimento da excelência seria fundamental para compreender o sistema de virtudes de Adam Smith, definida como "excelência, algo excepcionalmente grande e belo, que se eleva muito acima

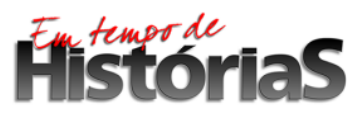


do que é vulgar e ordinário." (SMITH, 2002: 26). Pensando nesses termos, é possível diferenciar a atitude baseada na conveniência política e social de uma ação verdadeiramente virtuosa (HANLEY, 2009: 42-43).

Um último aspecto dessa corrupção dos sentimentos morais causada pela sociedade comercial refere-se à indiferença em relação aos pobres. Ao mesmo tempo em que o crescimento comercial promove uma distribuição da riqueza, permitindo uma melhora da condição social dos mais pobres, faz com que os mais ricos tenham uma indiferença cada vez maior com os mais fracos; em outras palavras, o sucesso comercial debilitaria nosso sentimento de simpatia para com eles (HANLEY, 2009: 45). Como afirma Hanley:

It is well known that Smith considered persistence of wealth inequalities to be a fundamental, even if lamentable, prerequisite for economic growth. Yet now Smith claims that such inequalities, even if instrumentally necessary for opulence, inhibit our most distinctively trait, namely our capacity for sympathy (HANLEY, 2009: 47).

Em síntese, os vícios e males da sociedade comercial percebidos por Adam Smith são: egoísmo, provocado pela vaidade e amor à superioridade; a inquietude e ansiedade, causada pela ambição e amor ao reconhecimento alheio; inautenticidade e duplicidade, induzidas pela vaidade; aceitação da mediocridade moral, como consequência dos prazeres advindos com o incremento do comércio; debilitação de nosso sentimento de simpatia e uma indiferença aos mais pobres e fracos (HANLEY, 2009: 52).

Smith não propõe "regras precisas", mas antes pretende apresentar uma ideia geral de comportamento virtuoso a que devemos aspirar chegar. Hanley denomina este sistema de ética moral de caráter normativo (HANLEY, 2009: 78; 81). Smith explicitou a natureza dessas regras na terceira parte de sua obra:

As regras gerais relativas a quase todas as virtudes, as que determinam quais as tarefas da prudência, da caridade, da generosidade, da gratidão, da amizade, são em muitos aspectos imprecisas e incertas, pois admitem muitas exceções, e exigem tantas modificações que é quase impossível regular nossa conduta inteiramente por respeito a elas (SMITH, 2002: 221).

Essas virtudes se diferenciam em qualidade e natureza da justiça, uma das poucas virtudes que possuem regras estritas - que Smith chama de "virtude negativa" (SMITH, 2002: 101):

As regras da justiça podem ser comparadas às regras de gramática; as regras das outras virtudes, às regras que os críticos estabelecem para alcançar o

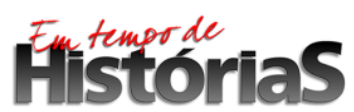


sublime e elegante na composição. As primeiras são precisas, exatas, indispensáveis; as outras, imprecisas, vagas, indeterminadas, e nos apresentam mais uma idéia geral da perfeição que deveríamos buscar, do que orientações certas e infalíveis para a atingir (SMITH, 2002: 213).

Mas, porquanto a justiça seja uma virtude negativa, posto que sua pura observância não "promove nenhum bem positivo" (SMITH, 2002: 101) - o que poderíamos fazer "sentando-nos, quietos e sem fazer nada" (SMITH, 2002: 102) - ela é essencial para a manutenção da sociedade, enquanto as demais virtudes não o são (FULTON, 1963: 46):

A sociedade, entretanto, não pode subsistir entre os que estão sempre prontos
a se ferir e ofender mutuamente. No momento em que tem início a ofensa,
no momento em que se instalam ressentimento e animosidade mútuos,
rompem-se todos os elos da sociedade, e os diferentes membros de que ela
consistia ficam como se dissipados e espalhados pela violência e oposição de
seus afetos discordantes. Se existe uma sociedade entre ladrões e assassinos,
estes pelo menos devem, segundo senso comum, abster-se de roubar e
assassinar uns aos outros. A beneficência é assim, menos essencial à
existência da sociedade que a justiça. A sociedade poderá subsistir, ainda
que não segundo a condição mais confortável, sem beneficência, mas a
prevalência da injustiça deverá destruí-la completamente. [...] [Os atos de
beneficência são] o ornamento que embeleza, não o alicerce que sustenta o
edifício [...]. A justiça, ao contrário, é o principal pilar que sustenta todo o
edifício (SMITH, 2002: 107)

Smith, no entanto, em seu estudo do caráter da virtude, na sexta parte de seu trabalho, praticamente deixa de lado a justiça e foca sua atenção nas virtudes ativas de prudência, justa magnanimidade e beneficência apropriada. Elas são apresentadas como as soluções para a corrupção da sociedade comercial (HANLEY, 2009: 93).

Contra os vícios da ansiedade, da inquietude, da duplicidade e inautenticidade, Smith defende a prudência. Esta virtude implicaria o "cuidado da saúde, da fortuna, da posição e reputação do indivíduo" (SMITH: 2002: 226). O homem prudente é, em grande medida, a negação do homem orgulhoso e vaidoso, uma vez que:

sempre estuda séria e determinadamente para entender o que professa entender, e não meramente para persuadir outras pessoas de que entende; e posto seus talentos nem sempre sejam brilhantes, são sempre perfeitamente genuínos. [...] é sempre sincero, e sente horror ao erro pensamento de exporse à desgraça que se segue da descoberta da falsidade. [...] é sempre capaz de manter amizades. [...] Se entra em novos projetos ou empreendimentos, provavelmente serão bem planejados e preparados. Jamais pode ser apressado ou impelido a eles por alguma necessidade, pois sempre dispõe de tempo e ócio para deliberar sóbria e lucidamente sobre quais serão suas prováveis consequências. $\mathrm{O}$ homem prudente não se predispõe a sujeitar-se a uma responsabilidade que não tenha sido imposta por seu dever [...] nem se

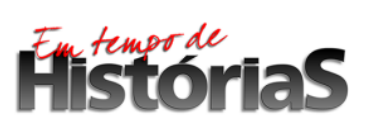

(PPGHIS/UnB) No. 26, Brasília, Jan- Jul 2015 ISSN 2316-1191 
intromete em assuntos alheios. [...] é avesso a meter-se em disputas, odeia facções, e nem sempre se prontifica a ouvir sequer a voz de uma ambição nobre e grande. [...] No fundo de seu coração, preferiria o deleite impassível da tranquilidade segura, não apenas a todo vão esplendor da ambição bemsucedida, mas à glória sólida e real de realizar as maiores e mais magnânimas ações (SMITH, 2002: 266-268).

Por toda sua preparação e seriedade de caráter, o homem prudente não cai nos vícios da vaidade ou do orgulho e mantém-se afastado da ansiedade e duplicidade de uma vida baseada em falsidades. Por outro lado, ao sempre deliberar sobre seus negócios e empreendimentos, pode saborear suas conquistas materiais com tranquilidade, não padecendo de uma vida inquieta.

Já a justa magnanimidade seria um antídoto ao vício da mediocridade moral abordado acima. Smith nos emula a um padrão de comportamento mais virtuoso quando define o homem sábio como aquele que busca sempre observar as regras da "exata conveniência e perfeição" (SMITH, 2002: 309), em detrimento daquele padrão de comportamento alcançado pela maioria dos homens:

O homem sábio e virtuoso dirige sua principal atenção para o primeiro padrão - a idéia da exata conveniência e perfeição. Existe no espírito de todo homem uma idéia desse tipo, gradualmente formada de suas observações sobre o caráter e conduta, tanto de si mesmo, como de outras pessoas. [...] No homem sábio e virtuoso, foram feitas com a mais aguda e delicada sensibilidade, e o mais extremo cuidado e atenção foram empregados ao fazê-las. [...] Imita, contudo, a obra de um divino artista, que jamais poderá ser igualada. Sente o êxito imperfeito de todos os seus melhores esforços, e vê com dor e aflição os distintos traços em que a cópia mortal fracassa perante o original imortal (SMITH, 2002: 309-310).

Hanley argumenta que Smith retoma, quando trata da magnanimidade, as virtudes clássicas de emulação do espírito e perfeição de comportamento (HANLEY, 2009: 132-174), contudo, com outro objetivo: ele não pretende formar só o estadista ou os grandes políticos e sim trazer essas virtudes para a maioria da população.

A beneficência, por sua vez, remediaria a indiferença aos pobres e a debilitação do sentimento de simpatia. Smith dedica a segunda seção da sexta parte de a Teoria dos sentimentos morais para a reflexão dessa virtude. De modo sintético, ele estabelece que nossa beneficência se dirige primeiramente para as pessoas que possuem vínculos conosco, em particular nossos familiares; depois se dirigem para aqueles com os quais compartilhamos os laços de amizade e gratidão; e, por fim, aqueles que se distinguem por sua situação extraordinária, os muito pobres e miseráveis e os muito ricos e afortunados (SMITH, 2002:

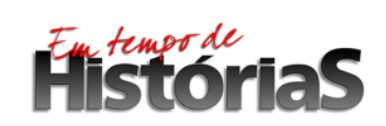

(PPGHIS/UnB) No. 26, Brasília, Jan- Jul 2015 ISSN 2316-1191 
283). Depois, ela se transporia para a beneficência em relação ao Estado em que se vive e então para a sociedade ou ordem de que faz parte dentro do país (SMITH, 2002: 285; 289). Mas essa virtude não tem barreiras e de certa forma se estende a todos os seres humanos:

Embora nossos eficazes bons serviços raramente possam ser estendidos para qualquer sociedade mais ampla do que nosso próprio país, nossa boavontade não está circunscrita por nenhuma fronteira, e pode, pois, abarcar a imensidão do universo. Não podemos formar a idéia de um ser inocente ou sensato cuja felicidade não desejamos, ou por cuja desgraça, quando claramente concebida pela imaginação não teríamos algum grau de aversão. A idéia de um ser nocivo, embora sensato, naturalmente provoca nosso ódio, mas a má-vontade que, nesse caso, temos com ele é realmente efeito de nossa benevolência universal. É efeito da solidariedade que sentimos pela miséria e ressentimento daqueles outros seres inocentes e sensatos, cuja felicidade sua malícia perturba (SMITH, 2002: 293-294).

E mais uma vez Smith nos exorta a um padrão de comportamento superior quando caracteriza o caráter benevolente do homem sábio:

A todo momento o homem sábio e virtuoso está disposto a sacrificar seu próprio interesse particular ao interesse público de sua própria ordem ou sociedade. Ademais, a todo momento está disposto a que o interesse de sua ordem ou sociedade seja sacrificado ao interesse maior do Estado ou da Soberania da qual é apenas parte subordinada. Deveria, pois, estar igualmente disposto a que todos esses interesses inferiores fossem sacrificados ao interesse maior do universo, ao interesse da grande sociedade de todos os seres sensatos e inteligentes dos quais o próprio Deus é administrador e diretor imediato (SMITH, 2002: 294-295).

Hanley afirma que nessas passagens sobre a beneficência Smith liga-se a outro tipo de tradição, a crista (HANLEY, 2009: 208), que prega "the whole-hearted love of God and the extension of such love to all of God's Creation, manifestating itself ultimately in the love of one's neighbor as one's self." (HANLEY, 2009: 176).

Ora, se todos estenderem seus sentimentos de beneficência aos demais que compõem a sua sociedade, uma vida mais justa e tranquila se seguiria (HIMMELFARB, 2011: 83). O que não significa o fim das diferenças sociais, como indicado acima. O próprio Smith deu um grande exemplo dessa beneficência universal:

suas finanças na época de sua morte, comparadas com sua vida muito modesta, confirmavam indubitavelmente o que as pessoas mais íntimas sempre suspeitaram: grande parte de suas economias anuais era destinada a serviços de caridade secreta (STEWART; SMITH, 2002: LXXIV). 
Prudência, magnanimidade e beneficência: eis as virtudes cultivadas pelo homem virtuoso. Sua prática pode vir a amenizar os problemas da sociedade comercial. Embora Smith admita que grande parte dos homens não alcança esse grau de excelência (SMITH, 2002:139-216), oferece-nos caminhos a percorrer e nos convida a uma vida de grandeza.

\section{Considerações finais}

Adam Smith foi um arguto observador de sua sociedade de seu tempo e percebeu que o desenvolvimento comercial, ao trazer uma distribuição maior da riqueza e do poder, poderia promover um empobrecimento moral e intelectual dos indivíduos. A corrupção causada pelo comércio poderia tornar os homens vaidosos, falsos, inautênticos, ansiosos e inquietos. De modo a evitar e mitigar os problemas desse estado de espírito corrupto, Smith propôs um sistema de moralidade prática. O estímulo das virtudes e de um comportamento mais moral viria das instituições presentes na sociedade. Para o filósofo escocês, o mercado, a justiça imparcial e a educação seriam as instituições privilegiadas para esse propósito. $\mathrm{O}$ desenvolvimento das virtudes - como a prudência, a magnanimidade e a beneficência poderia contrapor os efeitos nefastos do sistema comercial.

\section{Referências bibliográficas}

FITZGIBBONS, Athol. Adam Smith's system of liberty, wealth, and virtue. Nova York: Oxford University Press, 1995.

FULTON, Robert Brank. Adam Smith speaks to our times. Boston: The Christopher Publishing House, 1963.

GRISWOLD JR., Charles. Adam Smith and the virtues of Enlinghtenment. Nova York: Cambridge University Press, 1999.

HANLEY, Ryan Patrick. Adam Smith and the character of virtue. Cambridge: Cambridge University Press, 2009.

HIMMELFARB, Gertrude. Os caminhos para a Modernidade: os iluminismos britânico, francês e americano. São Paulo: Realizações Editora, 2011.

MULLER, Jerry Z. Adam Smith in his time and ours. New Jersey: Princenton University Press, 1995.

POCOCK, J. G. A. Linguagens do ideário político. São Paulo: Edusp, 2003.

SMITH, Adam. A riqueza das nações, vol. II. São Paulo: Nova Cultural, 1983.

Teoria dos sentimentos morais. São Paulo: Martins Fontes, 2002.

STEWART, Dugald. "Biografia crítica" In SMITH, Adam. Teoria dos sentimentos morais. São Paulo: Martins Fontes, 2002, pp. XI-LXXXII. 